\title{
PENERAPAN METODE PROFILE MATCHING SEBAGAI PENDUKUNG KEPUTUSAN PEMILIHAN JURUSAN PADA SMK AL HIDAYAH
}

\author{
Fintri Indriyani \\ Sistem Informasi Akuntansi \\ Universitas Bina Sarana Informatika Jakarta \\ fintri.fni@bsi.ac.id
}

\begin{abstract}
Abstrak
Pemilihan jurusan pada SMK Al Hidayah dilakukan pada saat siswa/siswi mendaftar di sekolah tersebut, dengan acuan nilai minimal tiga mata pelajaran memenuhi standard minimal nilai yang telah ditetapkan pihak sekolah untuk tiap jurusan. Penempatan jurusan dilakukan secara manual oleh panitia penerimaan siswa baru dengan melihat data nilai siswa dan minat siswa. Hal ini memiliki kelemahan dari sisi waktu tidak efisien dan juga memungkinkan kesalahan input oleh panitia penerimaan siswa baru. Sehingga diperlukan sebuah sistem berbasis komputer untuk membantu penentuan jurusan yang sesuai dengan kompetensi calon siswa. Metode Profile matching dalam penelitian ini digunakan untuk membantu mempercepat proses analisa kriteria nilai dan minat siswa disesuaikan dengan standard dari pihak sekolah. Kriteria nilai meliputi nilai matematika, bahasa inggris dan bahasa Indonesia, sedangkan pilihan jurusan ada akuntansi, administrasi perkantoran dan pemasaran. Hasil penelitian adalah rekomendasi jurusan sehingga dapat mempercepat proses penjurusan sesuai dengan profile masing-masing siswa.
\end{abstract}

Kata Kunci: Evaluasi Potensi, GAP, Profile Matching, Pemilihan Jurusan, Sistem Pendukung Keputusan.

\begin{abstract}
The selection of majors at Al Hidayah Vocational School is done when students enroll in the school, with a reference to a minimum of three subjects meeting the minimum standards of value set by the school for each department. Placement of majors is done manually by the new student admission committee by looking at student grades and student interests. This has weaknesses in terms of inefficient time and also allows input errors by the new student admissions committee. So we need a computer-based system to help determine majors that are in accordance with the competencies of prospective students. The Profile matching method in this study was used to help speed up the process of analyzing the value criteria and student interest according to the standards of the school. Criteria for grades include math, English and Indonesian languages, while the choice of majors is accounting, office administration and marketing. The results of the study are department recommendations so that they can accelerate the process of majors in accordance with the profile of each student.
\end{abstract}

Keywords: Potential Evaluation, GAP, Profile Matching, Selection of Departments, Decision Support Systems.

\section{PENDAHULUAN}

Sesuai dengan peraturan pemerintah no.29 tahun 1990 pasal 2 menyebutkan tujuan dari pendidikan menegah adalah meningkatkan pengetahuan siswa untuk melanjutkan pendidikan pada jenjang yang lebih tinggi dan untuk mengembangkan diri sejalan dengan perkembangan ilmu pengetahuan, teknologi dan kesenian dan meningkatkan kemampuan siswa sebagai anggota masyarakat dalam mengadakan hubungan timbalbalik dengan lingkungan sosial, budaya dan alam sekitarnya(Kebudayaan, n.d.). Pendidikan tingkat menengah di Indonesia secara global terbagi menjadi dua yaitu SMA dan SMK dimana untuk siswa yang ingin segera terserap di dunia kerja kebanyakan memilih untuk masuk ke SMK dikarenakan di SMK siswa diberi pembekalan materi yang lebih aplikatif dan memfokuskan pada keterampilan siswa didik.

SMK Al-Hidayah yang berlokasi di Cinere Depok merupakan salah satu sekolah kejuruan yang memiliki tiga jurusan yaitu akuntansi, administrasi perkantoran dan pemasaran, dimana para calon siswa yang ingin masuk ke sekolah ini dapat memilih jurusan sesuai keinginan mereka. Akan tetapi pihak sekolah juga memiliki standar minimum nilai yang digunakan untuk penempatan jurusan. Selama ini panitia penerimaan siswa baru SMK AL-Hidayah melakukan pendataan nilai dari tiga matapelajaran yaitu matematika, bahasa inggris dan bahasa Indonesia dan 
minat dari calon siswa, proses tersebut dilakukan secara manual (Pratama, 2016). Hal ini mengakibatkan proses penempatan jurusan menjadi lebih lama (Prabowo, Kusrini, \& Sunyoto, 2015) dan bisa jadi tidak sesuai dengan kompetensi calon siswa (Susilawati, 2017) sehingga proses yang ada menjadi tidak efektif dan efisien (Farida \& Firliana, 2016). Berdasarkan permasalahan tersebut maka penelitian ini dilakukan dengan tujuan untuk membantu pihak sekolah dalam mempercepat proses penempatan jurusan sesuai dengan kompetensi siswa. Pada penelitian terdahulu tentang pemilihan jurusan di perguruan tinggi STMIK Royal digunakan system pendukung keputusan menggunakan metode profile matching untuk memudahkan siswa dalam menentukam pilihan jurusan (Yuma \& Rizaldi, 2018). Ada pula pemilihan jurusan di MAN Gresik menggunakan metode profile matching dan metode SMARTER untuk pembobotan tiap kriterianya lalu diuji cobakan dengan 200 data siswa di bandingkan dengan perhitungan manual dari pihak sekolah sehingga disimpulkan bahwa metode profile matching dapat dijadikan sebagai bahan pertimbangan dalam penentuan jurusan dengan hasil 67,41\% keakuratan data (Afifah, Cahyani, \& Yunitarini, 2015). Dalam implementasinya metode ini juga bisa di terapkan di berbagai kasus diantaranya sebagai sistem penunjang keputusan untuk kenaikan jabatan dengan penggunaan metode ini bias meminimalisir penilaian sepihak atau subyektifitas dan mengurangi kesalahan dalam meloloskan calon pegawai yang sesuai dengan standar perusahaan (Frieyadie, 2016) Dapat pula diterapkan pada pemilihan ketua jurusan dengan melihat factor-faktor kemampuan yang dimiliki calon ketua jurusan (Anto \& Susilo, 2017).

\section{METODE PENELITIAN}

\section{Metode Penelitian}

Pada penelitian ini digunakan metode kuantitatif deskriptif untuk menentukan hubungan antara variabel dengan populasi dengan sekali pengukuran.

\section{Metode Pengumpulan data}

Data diambil dari panitia penerimaan siswa baru pada SMK Al-Hidayah yang merupakan data primer dengan metode wawancara dan dokumentasi. Data yang disajikan merupakan data tahun ajaran 2018/2019.

\section{Profile Matching}

Secara umum profile matching merupakan metode yang digunakan untuk membandingkan kompetensi objek penelitian dengan kompetensi yang diharapkan. Dari selisih hasil perbandingan didapatlah GAP, semakin kecil nilai GAP maka terdapat peluang besar untuk nilai prioritas karena nilai bobot semakin besar. Metode Profile matching dapat digunakan untuk menyelesaikan masalah semi terstruktur. Profile matching telah banyak digunakan dalam berbagai bidang untuk system pendukung keputusan diantaranya untuk penentuan kenaikan jabatan karyawan, pemilihan beasiswa, pemilihan mitra kerja termasuk juga pemilihan jurusan.

\section{Tahapan Penelitian}

Penelitian ini dilakukan dengan tahapantahapan yang mengacu pada tahapan metode profile matching (Kusrini, 2017) yang disesuaikan dengan objek penelitian yang ada, berikut adalah tahapannya:

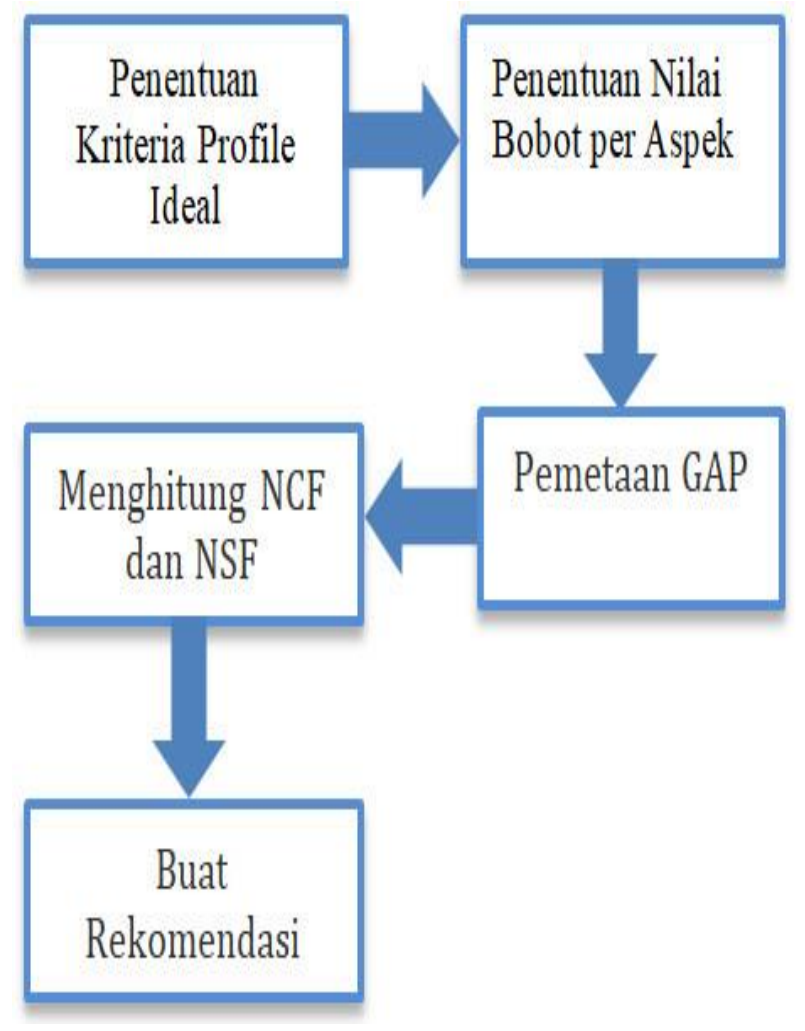

Sumber: (Indriyani, 2019)

Gambar 1. Tahapan Penelitian

Tahap pertama, Penentuan kriteria Profile Ideal. Pada tahap ini diambil nilai sebagai acuan di SMK AlHidayah untuk mata pelajaran Matematika, Bahasa Indonesia dan Bahasa Inggris yang menjadi syarat minimal untuk tiap jurusan.

Tahap kedua, Penentuan bobot per aspek. Pada tahap ini nilai per aspek dari setiap calon siswa di data sesuai dengan acuan input nilai. 
Tahap ketiga, Pemetaan GAP. Menghitung GAP dengan cara nilai mahasiswa per aspek dikurangi nilai profile ideal. Kemudian ditentukan nilai bobot sesuai dengan table GAP.

Tahap keempat, Menghitung NCF dan NSF. NCF didapat dari rata-rata bobot nilai per aspek per calon siswa. Nilai NSF didapat dari bobot nilai secondary factor. Adapun rumus mencari NCF adalah:

$N F C=\frac{\sum N C(a, n)}{\sum I C}$

Dimana

$\mathrm{NCF}=$ Nilai rata-rata Core Factor

$\mathrm{NC}(\mathrm{a}, \mathrm{n})=$ Jumlah total nilai core factor (matematika bahasa Indonesia dan bahasa inggris)

IC= Jumlah item Core Factor

Setelah nilai NCF dan NSF didapat maka dihitunglah nilai total dengan rumus $90 \%$ NCF ditambah $10 \%$ NSF dengan rumus sebagai berikut:

$N(a, n)=(x) \% N C F(a, n)+(x) \% N S F(a, n)$

Dimana

$\mathrm{N}(\mathrm{a}, \mathrm{n})=$ Total Nilai Aspek

$(\mathrm{x}) \%=$ Nilai persen yang diinput

$\operatorname{NCF}(a, n)=$ Nilai rata-rata Core Factor

$\operatorname{NSF}(a, n)=$ Nilai rata-rata Secondary Factor

Tahap kelima. Buat Rekomendasi. Pada tahap ini di data setiap calon siswa dibandingkan dan dipilih nilai terbesar sebagai rekomendasi.

\section{Objek Penelitian}

Objek penelitian adalah SMK Al-Hidayah yang didirikan pada tanggal 02 Mei 1998 dibawah Yayasan Pendidikan Islam AL-HIDAYAH CINERE yang diketuai oleh H. Abdullah H.M. Pada awal berdirinya SMK AL-HIDAYAH CINERE dipimpin oleh Bapak H.Ardani M. Nur SH, (alm). Adapun 3 jurusan yang disediakan yaitu Akuntansi, Sekretaris, dan Penjualan. Akuntansi merupakan jurusan dengan minat terbanyak dan dengan nilai standar tertinggi dibandingkan dua jurusan yang lain. Kemudian setelah berganti kurikulum jurusan tersebut berubah menjadi Akuntansi, Administrasi Perkantoran, dan Penjualan atau Pemasaran. Data diambil dari panitia penerimaan siswa baru sebanyak 67 calon siswa dari populasi 200 orang yang mendaftar di tahun ajaran 2018-2019 dengan menggunakan rumus Slovin dengan tingkat error $10 \%$ (Sugiyono, 2017) dengan penjabaran sebagai berikut:

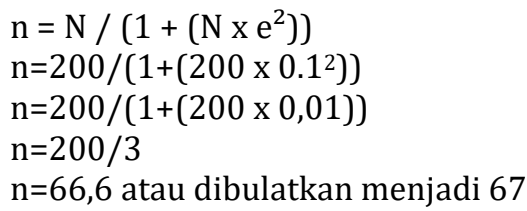

\section{HASIL PENELITIAN DAN PEMBAHASAN}

\section{Kriteria Profile Ideal}

Untuk Core Factor sesuai dengan kondisi real di SMK Al-Hidayah penjurusan dengan menimbang tiga nilai mata pelajaran yaitu Nilai Matematika, Nilai Bahasa Inggris dan Nilai Bahasa Indonesia, sedang untuk Secondary Factor digunakan minat calon siswa. Pertama kita tentukan dulu nilai profile ideal, seperti dijabarkan di table 1 dan 2 .

Tabel1. Tabel Acuan Input Nilai

\section{Nilai Sub Kriteria}

\begin{tabular}{|c|c|}
\hline Range & Besar Nilai \\
\hline$<64$ & 1 \\
\hline $65-74$ & 2 \\
\hline $75-84$ & 3 \\
\hline $85-94$ & 4 \\
\hline $95-100$ & 5 \\
\hline
\end{tabular}

Sumber: (Indriyani, 2019)

Tabel 2. Tabel Kriteria Nilai Profile Ideal

\begin{tabular}{lccc}
\hline JURUSAN/MAPEL & MTK & $\begin{array}{c}\text { Bhs } \\
\text { Ing }\end{array}$ & $\begin{array}{c}\text { Bhs } \\
\text { Ind }\end{array}$ \\
\hline Akuntansi & 2 & 2 & 2 \\
\hline $\begin{array}{l}\text { Administrasi } \\
\text { Perkantoran }\end{array}$ & 1 & 2 & 2 \\
\hline Pemasaran & 1 & 1 & 2
\end{tabular}

Sumber: (Indriyani, 2019)

\section{Penentuan Nilai Bobot Per Aspek}

Nilai setiap aspek dari masing-masing jurusan dihitung dengan standard yang telah ditetapkan diawal oleh panitia penerimaan siswa baru untuk setiap calon siswa baru, ditabel 3 disajikan nilai dengan perbandingan profile ideal untuk jurusan Akuntansi. Langkah yang sama juga dilakukan untuk jurusan administrasi perkantoran dan pemasaran. 
Tabel 3. Data Per Aspek di Jurusan Akuntansi

\begin{tabular}{cccccc}
\hline \multirow{2}{*}{ No } & Nama Siswa & MTK & $\begin{array}{c}\text { BHS } \\
\text { Ing }\end{array}$ & $\begin{array}{c}\text { BHS } \\
\text { Ind }\end{array}$ & $\begin{array}{c}\text { Minat } \\
\text { Siswa }\end{array}$ \\
\cline { 3 - 6 } 1 & $\begin{array}{c}\text { Nur Amelia } \\
\text { Hasanah }\end{array}$ & 3 & 3 & 3 & 1 \\
\hline 2 & Diela Ellandini & 1 & 2 & 2 & 1 \\
\hline 3 & $\begin{array}{c}\text { Nabillah Frana } \\
\text { Putri }\end{array}$ & 3 & 1 & 2 & 1 \\
\hline 4 & $\begin{array}{c}\text { Fitriani Apitah } \\
\text { Nurjanah }\end{array}$ & 2 & 1 & 3 & 1 \\
\hline 5 & Junaedi & 2 & 2 & 2 & 1 \\
\hline 6 & Ari Munfako & 2 & 1 & 1 & 2 \\
\hline 7 & $\begin{array}{c}\text { Raditya } \\
\text { Ludfianto }\end{array}$ & 2 & 1 & 1 & 1 \\
\hline 8 & $\begin{array}{c}\text { Al-Fath } \\
\text { Filsafah }\end{array}$ & 3 & 3 & 2 & 3 \\
\hline 9 & Rifaldy Ahmad & 2 & 1 & 1 & 2 \\
\hline 10 & $\begin{array}{c}\text { Ridwan Hadi } \\
\text { Putra }\end{array}$ & 1 & 3 & 1 & 3 \\
\hline & Profile Ideal & 2 & 2 & 2 & 1 \\
\hline Sumber: (Indriyani, 2019) & & &
\end{tabular}

\section{Pemetaan GAP}

Pada tahapan ini dibuat acuan GAP dan Bobot nilai dengan sesuai dengan pedoman tabel 4 .
Tabel 4. Tabel Bobot Nilai GAP

\begin{tabular}{ccl}
\hline GAP & $\begin{array}{c}\text { Bobot } \\
\text { Nilai }\end{array}$ & \multicolumn{1}{c}{ Keterangan } \\
\hline 0 & 3 & $\begin{array}{l}\text { Kompetensi sesuai dengan } \\
\text { profile Ideal }\end{array}$ \\
\hline 1 & 3.5 & $\begin{array}{l}\text { Kompetensi Individu } \\
\text { kelebihan 1 level }\end{array}$ \\
\hline-1 & 2.5 & $\begin{array}{l}\text { Kompetensi Individu } \\
\text { kekurangan 1 level }\end{array}$ \\
\hline 2 & 4 & $\begin{array}{l}\text { Kompetensi Individu } \\
\text { kelebihan 2 level }\end{array}$ \\
\hline-2 & 2 & $\begin{array}{l}\text { Kompetensi Individu } \\
\text { kekurangan 2 level }\end{array}$ \\
\hline 3 & 4.5 & $\begin{array}{l}\text { Kompetensi Individu } \\
\text { kelebihan 3 level }\end{array}$ \\
\hline 4 & 1.5 & $\begin{array}{l}\text { Kompetensi Individu } \\
\text { kekurangan 3 level }\end{array}$ \\
\hline-4 & 1 & $\begin{array}{l}\text { Kompetensi Individu } \\
\text { kelebihan 4 level }\end{array}$ \\
\hline
\end{tabular}

Sumber: (Indriyani, 2019)

Sehingga didapat nilai sebagai berikut untuk Jurusan Akuntansi.

Tabel 5. Pemetaan GAP

\begin{tabular}{clcccccccc}
\hline No & Nama Siswa & GAP & Bobot & GAP & Bobot & GAP & Bobot & GAP & Bobot \\
\hline 1 & Nur Amelia Hasanah & 1 & 4,5 & 1 & 4,5 & 1 & 4,5 & 0 & 5 \\
\hline 2 & Diela Ellandini & -1 & 4 & 0 & 5 & 0 & 5 & 0 & 5 \\
\hline 3 & Nabillah Frana Putri & 1 & 4,5 & -1 & 4 & 0 & 5 & 0 & 5 \\
\hline 4 & Fitriani Apitah Nurjanah & 0 & 5 & -1 & 4 & 1 & 4,5 & 0 & 5 \\
\hline 5 & Junaedi & 0 & 5 & 0 & 5 & 0 & 5 & 0 & 5 \\
\hline 6 & Ari Munfako & 0 & 5 & -1 & 4 & -1 & 4 & 1 & 4,5 \\
\hline 7 & Raditya Ludfianto & 0 & 5 & -1 & 4 & -1 & 4 & 0 & 5 \\
\hline 8 & Al-Fath Filsafah & 1 & 4,5 & 1 & 4,5 & 0 & 5 & 2 & 3,5 \\
\hline 9 & Rifaldy Ahmad & 0 & 5 & -1 & 4 & -1 & 4 & 1 & 4,5 \\
\hline 10 & Ridwan Hadi Putra & -1 & 4 & 1 & 4,5 & -1 & 4 & 2 & 3,5 \\
\hline Sumbering
\end{tabular}

Sumber: (Indriyani, 2019)

\section{Perhitungan NCF dan NSF}

Langkah selanjutnya adalah menghitung total Core Factor dengan menghitung rata-rata dari bobot nilai GAP dari core factor dan membandingkan dengan secondary factor dengan perbandingan $90 \%$ untuk core factor dan $10 \%$ untuk Secondary Factor. Seperti terlihat pada table 6. 
Tabel 6 Nilai NCF dan NSF Untuk Jurusan Akuntansi

\begin{tabular}{cllll}
\hline NO & Nama Siswa & CF & SF & NSK \\
\hline 1 & Nur Amelia Hasanah & 3,6 & 3 & 3,6 \\
\hline 2 & Diela Ellandini & 3,5 & 3 & 3,5 \\
\hline 3 & Nabillah Frana Putri & 3,1 & 3 & 3,1 \\
\hline 4 & Fitriani Apitah Nurjanah & 3,1 & 3 & 3,1 \\
\hline 5 & Junaedi & 3,8 & 3 & 3,7 \\
\hline 6 & Ari Munfako & 3 & 4 & 3,1 \\
\hline 7 & Raditya Ludfianto & 3 & 3 & 3 \\
\hline 8 & Al-Fath Filsafah & 3,8 & 5 & 3,9 \\
\hline 9 & Rifaldy Ahmad & 3 & 4 & 3,1 \\
\hline 10 & Ridwan Hadi Putra & 3,4 & 5 & 3,5 \\
\hline Sumber (Indriyani, 2019$)$ & & &
\end{tabular}

Sumber: (Indriyani, 2019)

\section{Rekomendasi}

Langkah terakhir adalah membuat rekomendasi dengan cara membandingkan nilai akhir dari setiap jurusan dan hasil rekomendasi diambil dari nilai tertinggi. Seperti terlihat di tabel 7.

Tabel 7. Rekomendasi Jurusan dengan Metode

\begin{tabular}{|c|c|c|c|c|c|}
\hline No & Nama & $\begin{array}{c}\text { NSK } \\
\text { AK }\end{array}$ & $\begin{array}{c}\text { NSK } \\
\text { AP }\end{array}$ & $\begin{array}{c}\text { NSK } \\
\text { PM }\end{array}$ & Rekomendasi \\
\hline 1 & $\begin{array}{l}\text { Nur } \\
\text { Amelia } \\
\text { Hasanah } \\
\end{array}$ & 3,5625 & 3,3375 & 3,3375 & 1 \\
\hline 2 & $\begin{array}{l}\text { Diela } \\
\text { Ellandini }\end{array}$ & 3,45 & 3,675 & 3,7875 & 3 \\
\hline 3 & $\begin{array}{l}\text { Nabillah } \\
\text { Frana } \\
\text { Putri }\end{array}$ & 3,1125 & 2,8875 & 3,3375 & 3 \\
\hline 4 & $\begin{array}{l}\text { Fitriani } \\
\text { Apitah } \\
\text { Nurjanah }\end{array}$ & 3,1125 & 3 & 3,45 & 3 \\
\hline 5 & Junaedi & 3,675 & 3,5625 & 3,675 & 1 \\
\hline 6 & $\begin{array}{l}\text { Ari } \\
\text { Munfako }\end{array}$ & 3,1 & 2,9875 & 3,4375 & 3 \\
\hline 7 & $\begin{array}{l}\text { Raditya } \\
\text { Ludfianto }\end{array}$ & 3 & 2,8875 & 3,3375 & 3 \\
\hline 8 & $\begin{array}{l}\text { Al-Fath } \\
\text { Filsafah }\end{array}$ & 3,875 & 3,65 & 3,65 & 1 \\
\hline 9 & $\begin{array}{l}\text { Rifaldy } \\
\text { Ahmad }\end{array}$ & 3,1 & 2,9875 & 3,4375 & 3 \\
\hline 10 & $\begin{array}{l}\text { Ridwan } \\
\text { Hadi } \\
\text { Putra }\end{array}$ & 3,5375 & 3,7625 & 3,7625 & 3 \\
\hline
\end{tabular}

Sumber: (Indriyani, 2019)

\section{SIMPULAN DAN SARAN}

\section{Simpulan}

Penerapan metode Profile Matching dalam menentukan jurusan pada SMK Al-Hidayah dapat menghasilkan rekomendasi jurusan sesuai profile standar yang ditentukan pihak sekolah, dengan menghitung nilai GAP kompetensi siswa dan standard ideal. Sehingga dalam menentukan jurusan tidak hanya berdasarkan pilihan dari siswa seperti yang berlangsung saat ini, sehingga didapat hasil yang lebih baik dan efektif. Dengan adanya penelitian ini panitia penerimaan siswa baru pada SMK Al-Hidayah diberikan kemudahan dalam menentukan jurusan untuk calon siswanya sehingga proses pendataan menjadi lebih cepat.

\section{Saran}

Untuk pengembangan lebih lanjut dan agar pihak sekolah mudah dalam penggunaan metode ini maka perlu dibuat sebuah aplikasi dengan acuan metode profile matching. Apabila dirasa perlu dapat dikembangkan menjadi Expert System.

\section{DAFTAR REFERENSI}

Afifah, N., Cahyani, A. D., \& Yunitarini, R. (2015). SISTEM PENDUKUNG KEPUTUSAN PENENTUAN JURUSAN UNTUK SISWA MAN GRESIK DENGAN METODE PROFILE MATCHING. Jurnal Sistem Informasi Indonesia, 1(1). Retrieved from http://www.publications.aisindo.org/index.ph $\mathrm{p} / \mathrm{JSII} /$ article/view/4

Anto, A., \& Susilo, T. (2017). Penerapan Metode Profile Matching pada Sistem Pendukung Keputusan Pemilihan Ketua Program Studi ( STUDI Kasus: Program Studi Teknik Informatika STMIK Musi Rawas ), $V$ (November), 87-93.

Farida, I. N., \& Firliana, R. (2016). Implementasi Metode Profile Matching Untuk Evaluasi Potensi Akademik Penjurusan Siswa MAN 2 Kota Kediri. JURNAL INFOTEL - Informatika Telekomunikasi Elektronika, 8(2), 156. https://doi.org/10.20895/infotel.v8i2.121

Frieyadie, F. (2016). PENGGUNAAN METODE PROFILE MATCHING UNTUK SISTEM PENUNJANG KEPUTUSAN KENAIKAN JABATAN PADA INSTANSI PEMERINTAH. Paradigma - Jurnal Komputer Dan Informatika, 18(2), 75-80. https://doi.org/10.31294/P.V18I2.1228

Indriyani, F. (2019). Laporan Akhir Penelitian: Sistem Pendukung Keputusan Pemilihan Jurusan Pada Smk Al Hidayah. Jakarta.

Kebudayaan, K. P. dan. (n.d.). Peraturan Pemerintah 
No.29 Tahun 1990 tentang Pendidikan Menengah.

Kusrini. (2017). Konsep dan Aplikasi Sistem Pendukung Keputusan. Yogyakarta: Andi + AMIKOM.

Prabowo, Y. S., Kusrini, K., \& Sunyoto, A. (2015). Sistem Pendukung Keputusan Pemilihan Jurusan SNMPTN Bagi Siswa SMAN 7 Purworejo. In Proceedings Konferensi Nasional Sistem dan Informatika (KNS\&I) (Vol. 0, pp. 180-185). Bali: STMIK STIKOM. Retrieved from http://www.ejournal.stikombali.ac.id/index.php/knsi/article/view/438

Pratama, R. P. (2016). SISTEM PENDUKUNG KEPUTUSAN PENJURUSAN SISWA PADA SMAN 5 KEDIRI DENGAN MENGGUNAKAN METODE PROFIL MATCHING. Universitas Nusantara PGRI Kediri. Retrieved from http://simki.unpkediri.ac.id/mahasiswa/file_a rtikel/2016/11.1.03.03.0230.pdf

Sugiyono. (2017). Metode Penelitian Kuantitatif, Kualitatif, dan R\&D. Bandung: Alfabeta.

Susilawati, S. (2017). Perangkat Lunak Berbasis Website Untuk Membantu Pemilihan Jurusan di SMK Negeri 10 Pandeglang. In Prosiding Seminar Nasional Riset Terapan / SENASSET (pp. 26-32). Serang: Universitas Serang Raya. Retrieved from http://ejurnal.lppmunsera.org/index.php/senasset/ar ticle/view/420

Yuma, F. M., \& Rizaldi, R. (2018). SISTEM PENDUKUNG KEPUTUSAN DALAM PEMILIHAN JURUSAN DI PERGURUAN TINGGI DENGAN METODE PROFILE MATCHING. Seminar Nasional Royal (SENAR), 1(1), 181-184. Retrieved from https://jurnal.stmikroyal.ac.id/index.php/sen ar/article/view/164 